\title{
Scientist Spotlight: Kerry Bloom
}

Received: 30 August 2021 / Revised: 30 August 2021 / Accepted: 1 September 2021 / Published online: 16 October 2021 (C) Springer Nature B.V. 2021

Scientist Spotlights are short articles, published periodically, that highlight established and emerging leaders in chromosome and genome research. In each article, the featured scientist answers a defined set of questions that reveal their academic and scientific path to their current position, the events or experiences that cultivated their interest in science, their own scientific discoveries that most excite them, and extracurricular activities that have shaped who they are as a scientist and human being. The Editorin-Chief, Executive Editor, and Associate Editors of Chromosome Research will solicit scientists to be highlighted, but suggestions and/or self-nominations from the readership are also encouraged.

Editor's Note: In this new series, we ask emerging and established leaders in chromosome and genome biology to share their thoughts on science, mentoring, and career choices. The articles offer a glimpse into the diversity of research, professional paths, and perspectives on science and life within our chromosome research community.

Our inaugural Scientist Spotlight focuses on Kerry Bloom, the Thad L. Byle Distinguished Professor and Chair of the Biology Department at

Responsible Editors: Rachel O’Neill and Beth Sullivan
University of North Carolina, Chapel Hill. Kerry's lab studies mitosis, with a particular emphasis on kinetochore assembly. His lab uses genetics, molecular biology, and biophysics to explore the dynamics and quantitative properties of spindle microtubules, centromeres, and chromosomes. Kerry received his B.S. from Tulane University, and his $\mathrm{PhD}$ from Purdue University. He was a postdoctoral fellow at University of California, Santa Barbara before joining the faculty at University of North Carolina, Chapel Hill. He is an active member and leader in the American Society of Cell Biology and was elected to the National Academy of Sciences in 2021.

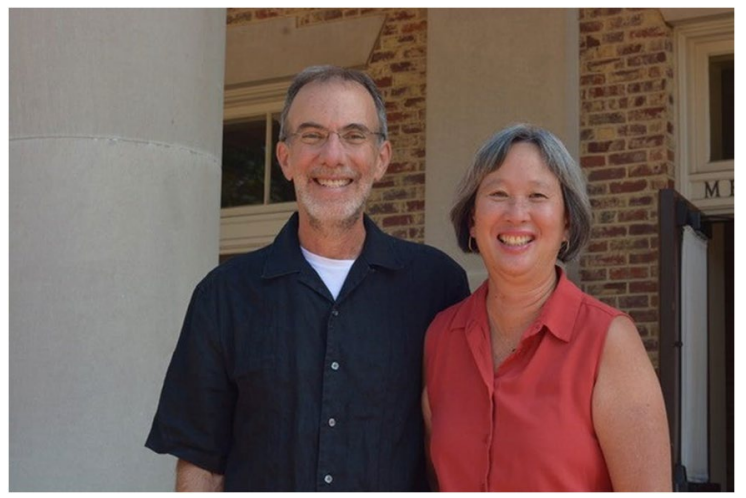

Kerry Bloom and his partner/wife in science and life Elaine Yeh 


\section{Q: How did you become interested in science and what was your path through undergraduate, graduate school, and postdoctoral training? Were there major lessons you learned along the way?}

KB: I should start by saying that I had no idea what graduate school was, or what a career in academia was. My parents were in business, and it was drummed into me at an early age that an interest in Biology translated into a pre-med path. My first hint of research was through a High School program where we found a lab at one of the local Universities to volunteer. I landed in the lab of Dr. Stanley Falkow, then at Georgetown University. My job was to collect water from the Potomac River and analyze samples looking for Salmonella. What an amazing experience. I remember sitting in Dr. Falkow's office, hearing him talk about DNA and captivated at how interested he was. I had not seen anyone that interested in their "day job". Needless to say, we found Salmonella, and I got my first taste of research.

I went to Tulane University for college, picked in large part with the use of a compass to find schools that were within a 24-h drive from Washington D.C. (I was allowed to be a day's drive away from home). While I don't recommend this as a general strategy, it is the first of many random walks that have been formative in my career. I ended up in the lab of Dr. Erik Ellgaard working with two graduate students, Mike Innis and Mark Harpold. As I was applying to medical school, they asked me what I was doing. How could anyone question the "prime directive"? They proceeded to enlighten me about graduate school, and I sent applications to both medical and graduate school. This was in the mid-70's and hence my applications were heavily weighted toward the west coast. $100 \%$ rejection! (Even though I graduated Magna Cum Laude, I couldn't overcome dismal standardized test scores). I can't say I remember being particularly devastated except that my dream of landing in California would be delayed. I applied to graduate school at Purdue University through the recommendation of my advisor Dr. Ellgaard. The lessons were starting to crystalize: life is about the path, however convoluted it seems.

Purdue University is due north of New Orleans, making no progress moving my trusty compass west. Upon arrival at Purdue, I worked in Dennis Smith's laboratory, who was toiling away on something that activated cell cycle progression (later discovered to be MPF) and analyzing genome and transcript complexity via nucleic acid hybridization in early amphibian development. Dale Graham had just arrived from the Britten/Davidson laboratories at CalTech and our class on $\mathrm{C}_{\mathrm{o}} \mathrm{t}$ and $\mathrm{R}_{\mathrm{o}} \mathrm{t}$ curves was nothing like any class I had taken before. These people were "into it". The excitement and depth of inquiry was palpable. I was able to attend the Embryology course at the Marine Biological Laboratory at Woods Hole in the summer of 1976, where Lynna Hereford and Michael Rosbach were teaching. Another amazing experience. Scientists have emotions, volatile at times, but it seemed that nothing was done without passion.

Upon getting back to Purdue, a young professor, John Anderson just showed up from Stanford University having worked with Bob Schimke. They were cloning genes! How cool. We started hanging out, having lunch on Saturdays at the local hot dog stand and the occasional beer at the town bar. I switched to John's lab, without appreciating lab allegiance. In retrospect I would do it over again, but the emotional cost was not insignificant. A lesson here is that taking risks is part of the process. There are times it is important to follow your heart.

I learned science in John's laboratory. We discovered that transcriptionally active genes were more susceptible to nuclease digestion than inactive genes. Nucleosomes were just being discovered, and lo and behold, genes were differentially organized at the nucleosome level. There were several influential papers at the time (Weintraub and Groudine) and during the writing, John taught me to focus on the data. Let the data guide the thinking. Ideas come and go, but good data will stand the test of time. This has also served me well. A challenge to this day is to read the same paper, but from differing perspectives. There is the author's perspective, but there are always alternative hypotheses. It is hard, but worth the effort to look at data from a differing vantage point. This obviously has significant implications at many levels in our field and societal interactions.

For all the great science I was learning, there was a dearth of anything outside the lab. I had no idea that people went to meetings, I had no inkling of grants or the NIH and I still had no idea as to how one formed a career or any insight into the culture of our profession. Hence, having defended my thesis I began to write letters for postdoctoral positions, 
indicating my immediate availability. Needless to say, most of the laboratories would not be able to consider my application until the following year. One laboratory, John Carbon at the University of California Santa Barbara, had a position and I jumped at the chance. When I asked about a visit, John asked me why. The laboratory hugs the Pacific Ocean and he couldn't understand what I needed to know about the science that I could not get from his publications. I did not visit the laboratory before committing.

While I learned science at Purdue, I learned how to be a scientist at UCSB. My primary mentor was a postdoctoral fellow, Molly Fitzgerald-Hayes. Molly is the one who listened to my practice talks, who lead me (literally holding my hand) at national meetings and educated me about academia. John Carbon taught by example. He and his wife, Louise Clarke did all their own experiments and worked quietly in an adjacent lab. They thought through the steps of each experiment, would a given result allow you to distinguish among the possibilities, would it aid you in the deciding the next step. The lesson to the rest of us and now mantra: Would John and Louise do this experiment? This manifests as the following dialog with my students: Okay let's say you get this result, what does that tell you, what will you do next? A second tenet of John Carbon's was controls. I'll never forget his admonition: you can never do all the controls, do the right one. I try my best on this one.

\section{Q: What is the most exciting discovery you have made in your own research program and/or could you describe a recent line of work of which you are most proud?}

KB: As we all know, we don't do this job for the Eureka moments. They are few and far between. When I pulled the autoradiograph of the Southern blot with centromere chromatin structure, I had no clue what was hiding in there. Likewise, looking at cytoplasmic dynein fused to GFP with fluorescent light and seeing little wisps of dynamic microtubules didn't prepare me for our adventure in live cell microscopy, nuclear migration, spindle positioning and the cytoskeleton. The centromere bottlebrush had a similarly inauspicious beginning. My wife Elaine Yeh was imaging cohesin-GFP in live cells and saw a fluorescent donut around the spindle in metaphase. This made no sense. Cohesin is supposed to hold sister centromeres together to resist forces from microtubules pulling on bi-oriented kinetochores. What was cohesin doing off the spindle axis and organized into such a seemingly uniform structure?

I digress for a major life-lesson, that of reinvention. It is so important to look at life in new ways and retain that sense of joy upon new discoveries. It's hard to do this in a field you've been in for decades. If one reinvents oneself, you find yourself in a new field and a fresh perspective. The lyrics from The Talking Heads' Once in a Lifetime: "How did I get here, How do I work this, What is this beautiful house?" are my inspiration.

I have gone through several transformations in my career. I was trained in chromatin as a graduate student and applied those techniques to the yeast centromere as a postdoctoral fellow in the 80's. At UNCChapel Hill, my lab was fortuitously placed next to Ted Salmon, an expert in light microscopy. We transitioned to live cell microscopy with Ted's help applying DIC microscopy (differential interference contrast) to watch yeast cells divide in real time. Upon the discovery of GFP in the mid 90's we cemented a long and fruitful collaboration with Ted Salmon. A second transition was into the world of polymer physics another decade later. In order to understand cohesin function in the centromere and to address the problem from a physics perspective and not from the dogma in the field, we thought we should try to model the centromere DNA. The centromere DNA itself was not behaving according to simple models, thus we had plenty of cause from our data to question major assumptions in the field.

We started the foray into physics with a new set of UNC collaborators, Russ Taylor and Leandra Vicci in the Computer Science department. We would meet for hours once a week with undergraduate and graduate students and teach each other polymer physics and biology, respectively. We got to the bottlebrush by slogging through the data, not violating Newton's laws, and identifying the simplest of models that capture the findings. Of course, when we got there, we find out the bottlebrush is nothing new for polymer physicists. It is a common solution to the problem of amplifying tension with a floppy polymer. A renowned figure in the field, Dr. Michael Rubinstein who literally wrote the major text in the field (Polymer Physics, Rubinstein 
and Colby) was in the Chemistry department at UNC. We presented the data to Michael and several of his colleagues for vetting. I must have been in my early 50 's at the time. For all intents and purposes, this was a prelim examination. Here I was presenting a model to experts in the field who know more than I will ever know about the behavior of polymers. An important coda is that while working towards the model was so exhilarating, I tell my students daily to break it. We need to remain its deepest sceptics.

I have a third transition looming in my future, recombination, that I hope will reveal new secrets within the centromere.

\section{Q: What is your mentorship style? How have you arrived at that style, and did you use specific resources to learn or enhance your mentoring?}

$\mathrm{KB}$ : The most honest answer here is that this is a work in progress. I feel like my style is completely different from when I started. As an insecure Assistant Professor, I was definitely hands-on. I needed to see the data as it came out of the developer or the stain. I still like to see the data but am much more patient and let students dictate when they're ready to show me. It has taken years to deeply appreciate that different students have different needs. One thing I tell students is that in choosing a laboratory, don't base it on the project, rather base it on how comfortable you are around the PI. What will dictate your success is how well you interact with your mentor. I know I cannot be all things to all students. I try to figure out a student's strengths and weaknesses, what kind of learner they are, and do my best to tailor my style accordingly.

\section{Q: If you had not chosen a career in academic research or chromosome biology, what career would you have pursued?}

KB: This question has come up multiple times in my career, first at my failed interviews for medical school. But the form was slightly different: "What will you do if you don't get into Medical School?" I am passionate about motorcycles and am pretty sure I would have been content as a motorcycle mechanic. I worked in a motorcycle shop one summer when I was an undergraduate and continued to work on them in my backyard or basement until several years ago. I am a tactile learner and if possible, I need to put the nuts and bolts together to see how they work. With respect to life sciences, I think of this as a mechanical engineer, how are structures built, how do they work and how are they torn down. I was not intimidated by physics or microscopy-they are things I can tinker with. In contrast, I think of electrical engineering as circuitry. How is information transmitted, how are signals amplified and attenuated. I do not think like an electrical engineer, and to this day have trouble with the genetic concepts of positive or negative feedback.

\section{Q: What is the best or most helpful professional advice you have received?}

KB: Don't take anything personally. The more criticism the better and the sooner you dissociate any feelings of inadequacy, the sooner you will be able to constructively address questions about your work.

I have gained much more understanding from sharing results early and discussing ideas freely with colleagues. I can count one time in my career that we were "burnt", and someone beat us to publication based on a discussion we had early on. There is no way I would trade a lifetime of free exchange for the few negative outcomes.

Let the data be your guide, not dogma. This is much easier said than done. Try to read papers questioning the author's conclusions, not their data.

\section{Q: When you are not doing science what do you enjoy doing?}

KB: My years of motorcycling and running marathons are in the past. I enjoy my commute into work (walking 2 miles each way) and hikes with my wife, daughter, her boyfriend, and our granddaughter. We are a few hours from Asheville, our hideaway in the mountains, where we enjoy trails, art, pottery and food.

Publisher's note Springer Nature remains neutral with regard to jurisdictional claims in published maps and institutional affiliations. 